\title{
Which quadrant is less painful for intravitreal injection? A prospective study
}

\author{
Saeed Karimi ${ }^{1} \cdot$ Seyed Aliasghar Mosavi ${ }^{1} \cdot$ Khosrow Jadidi $^{2} \cdot$ Homayoun Nikkhah $^{1} \cdot$ Bahareh Kheiri $^{1}$
}

Received: 5 April 2018 / Revised: 3 June 2018 / Accepted: 17 July 2018 / Published online: 10 September 2018

(C) The Royal College of Ophthalmologists 2018

\begin{abstract}
Purpose: To evaluate the relationship between injection site and pain severity following intravitreal injection of bevacizumab (IVB).

Design: Prospective, randomized, four-armed, clinical trial.

Methods: The present study was a prospective, randomized, four-armed clinical trial, which included 1004 eyes from 1004 patients. Patients receiving IVB were randomly assigned into four groups: superotemporal (ST); superonasal (SN); inferotemporal (IT); and inferonasal (IN) injections. The visual analog scale (VAS) was used to assess pain. Primary study variables were the relationship between pain severity and injection site, number of previous injections, age, sex, and indication for injection. Secondary variables included best-corrected visual acuity (BCVA) and central macular thickness (CMT) changes 1 month post IVB.

Results: Overall mean pain score was $2.86 \pm 2.2$. Indications for injection were diabetic macular edema $(84.1 \%)$, neovascular age-related macular degeneration (7.7\%), and macular edema secondary to retinal vein occlusion (8.2\%). The mean VAS scores in the SN, IN, ST, and IT groups were $1.5 \pm 1.7,3 \pm 2.3,4 \pm 2$, and $3 \pm 2.1$, respectively. Pain severity was significantly correlated with injection site $(p<0.001)$ and $\operatorname{sex}(p<0.001)$; females showed higher pain scores. A negative correlation existed between pain score and number of previous injections $(p=0.03)$. Pain severity was not associated with age $(p=0.659)$, lens status $(p=0.478)$, vitreous reflux $(p=0.648)$, or indication for injection $(p=0.390)$. No significant complications were observed.

Conclusions: ST quadrant was the most painful and SN quadrant was the least painful sites for IVB. Pain severity score was significantly associated with injection site, number of injections, and sex.
\end{abstract}

\section{Introduction}

Over the last 10 years, intravitreal injection of anti-vascular endothelial growth factor (anti-VEGF) agents has attracted much attention among retina specialists and become one of the most common intraocular procedures [1]. Intravitreal injections are performed in the treatment of a variety of ocular diseases, including neovascular age-related macular degeneration (AMD), diabetic macular edema (DME), and

Seyed Aliasghar Mosavi

a.a.mosavi@gmail.com

1 Ophthalmic Research Center, Shahid Beheshti University of Medical Sciences, Tehran, Iran

2 Department of Ophthalmology, Baqiyatallah University of Medical Sciences, Tehran, Iran retinal vascular occlusions (RVO) [2-4]. Bevacizumab and ranibizumab are the most widely used anti-VEGF agents [5, 6]. In the United States, it is estimated that over 100000 intravitreal injections are performed monthly. This might become the most common intraocular procedure worldwide [7]. There are many techniques for intravitreal injection, and various practices in terms of aseptic technique, anesthetic use, prophylactic antibiotics, post-injection monitoring, and treatment protocols [8-11]. However, there is little agreement among clinicians regarding acceptable injection techniques $[12,13]$.

The best site for intravitreal injection is unclear, and the correlation between injection site and severity of pain is not well understood. Patient distress at the time of injection results in sudden movements of the eye leading to intraocular complications and consequently unpleasant experiences, after which patients are less likely to continue intravitreal injections [14]. As many patients require 
multiple intravitreal injections, it is essential to minimize pain during the procedure to maximize subsequent compliance.

Pain is a subjective perception with high inter-individual variability that can be measured using several scores, such as the visual analog pain scale and the numeric pain rating scale $[14,15]$. To the best of our knowledge, only two studies have investigated pain associated with IVB injection site, and the authors found no statistically significant difference between quadrants [16, 17]. Most studies compared anesthetic methods preceding the injection; however, none have reported a statistically significant difference in overall pain reported by the patients $[18,19]$. Tunneled injection has been shown to decrease vitreous reflux and loss of injected drug, but no difference in patient pain has been found between tunneled and straight intravitreal injections [20, 21]. Moreover, it has also been suggested that smaller gauge needles (29-30 G) are associated with reduced pain [20]. Several guidelines have been developed to standardize the procedure, especially in order to reduce the risk of endophthalmitis [22, 23]. However, despite the common use of intravitreal injections, there are no uniform clinical guidelines or consensus on the site or quadrant location used for injection [22], which varies according to the surgeon's discretion. The aim of this study was to investigate the effect of injection site on pain severity among patients receiving intravitreal injection of bevacizumab (IVB).

\section{Materials and methods}

This prospective, randomized, four-armed clinical trial was carried out to evaluate the effect of injection site on the severity of pain associated with IVB. The study was performed in accordance with the tenets of the Declaration of Helsinki and the guidelines of the local ethics committee. This study was registered on clinical trials.gov (identifier, NCT02790775). A written informed consent was obtained from all study patients. We included patients with DME, AMD, and RVO who visited our retina clinic and were candidates for IVB injection. Inclusion criteria included indication for IVB and ability to score and report pain perception. Exclusion criteria included being younger than the age of 18 , ocular pain prior to the procedure, history of myocardial infarction or cerebrovascular events in the last 6 months, history of all kinds of anterior segment conditions affecting pain sensation such as herpetic eye disease, dry eye syndrome, limbal stem cell deficiency, uveitis, epithelial basement membrane dystrophy, recurrent corneal erosion, significant contact lens-associated red eye, corneal hydrops associated with keratoconus, iatrogenic and medica mentosa-induced corneal damage, episcleritis, scleritis, angle closure, and bullous keratopathy, history of using systemic analgesic or sedative medications in the last 3 months, history of previous and/or current use of drops that may affect the sensitivity of the eye surface, previous eye surgery other than cataract surgery, keratitis and poor cooperation in the visual analog scale (VAS) usage. To gain a power of $90 \%$ to detect 0.5 unit of VAS pain score difference between injection sites, when the type I error was set to be 0.05 and the standard deviation of pain on $0-10$ scale was believed to be 1.7 based on previous studies $[16,17]$, a minimum sample of 246 eyes was required in each site. To compensate a possible loss of information, we enrolled 251 eyes in each group. Thus, 1004 eyes of 1004 patients were included in this study, and each patient received a referral number from 1 to 1004 based on the order of referral for intravitreal injection. Permuted block randomization with the varied length $(4,8,12$, and 16$)$ was used to randomize enrolled patients into four groups (superotemporal (ST), superonasal (SN), inferotemporal (IT), and inferonasal (IN)) for receiving IVB.

The injection was performed in one of abovementioned quadrants randomly. The patients were referred for injection by retina specialists between 1 December 2015 and 30 May 2016. Each participant received one injection in one eye. Before enrolling, all patients underwent complete ophthalmic examination. Additional parameters were also recorded, including age, sex, type of disease, number of previous injections in the injected eye, diabetes mellitus (DM), lens status, severity of pain associated with the injection, postinjection reflux, BCVA using Snellen chart and central macular thickness (CMT) using optical coherence tomography. The patients were instructed on using the VAS system prior to the injection, by a nurse who was blind to the study. The patients were then interviewed immediately (within $2 \mathrm{~min}$ ) after IVB injection to score their perceived pain during the injection on a VAS of 0 (no pain) to 10 (unbearable/worst pain). The same surgeon (SAM) performed all injections. The interviewing nurse was blind to the study, but the injecting physician and the patients could not be masked to the study groups. Nonetheless, injection sites were determined by permuted block randomization based on the referral number of the patients, and the injecting surgeon was not allowed to change the injection site.

Mean pain score was considered as the primary outcome measure. IVB was prepared and administered according to previously reported guidelines [23]. All intravitreal injections were performed aseptically in the supine position. All patients received the same anesthesia [two drops of topical tetracaine $\mathrm{HCl} 0.5 \%$ (TetraVisc; Ocusoft) in the inferior culdu-sac, 1 min apart] 10 min prior to injection. We applied topical tetracaine because the topical tetracaine $0.5 \%$ was reportedly as effective as lidocaine $0.5 \%$ and provided excellent anesthesia for intravitreal injections [24]. Patients 
Table 1 Patient demographics and baseline characteristics

\begin{tabular}{|c|c|c|c|c|c|c|}
\hline \multirow[t]{2}{*}{ Variable } & \multirow[t]{2}{*}{ Total } & \multicolumn{4}{|l|}{ Injection site } & \multirow{2}{*}{$p$-Value } \\
\hline & & IN & IT & $\mathrm{SN}$ & ST & \\
\hline$n$ & 1004 & 251 & 251 & 251 & 251 & - \\
\hline \multicolumn{7}{|l|}{ Age } \\
\hline Mean \pm SD & $61.3 \pm 10.4$ & $60.5 \pm 11.3$ & $62.2 \pm 10.7$ & $61.1 \pm 10.2$ & $61.4 \pm 9.1$ & \multirow[t]{4}{*}{$0.322^{\mathrm{a}}$} \\
\hline Median (range) & $60(19$ to 90$)$ & 60 (21 to 90$)$ & 61 (30 to 90$)$ & $60(23$ to 90$)$ & 61 (19 to 90$)$ & \\
\hline$\leq 65$ & $686(68.3 \%)$ & $165(65.7 \%)$ & $151(60.2 \%)$ & $178(70.9 \%)$ & $192(76.5 \%)$ & \\
\hline$>65$ & $318(31.7 \%)$ & $86(34.3 \%)$ & $100(39.8 \%)$ & $73(29.1 \%)$ & $59(23.5 \%)$ & \\
\hline \multicolumn{7}{|l|}{ Sex } \\
\hline M & $488(48.6 \%)$ & $117(46.6 \%)$ & $121(48.2 \%)$ & $127(50.6 \%)$ & $123(49.0 \%)$ & \multirow[t]{2}{*}{$0.842^{\mathrm{b}}$} \\
\hline $\mathrm{F}$ & $516(51.4 \%)$ & $134(53.4 \%)$ & $130(51.8 \%)$ & $124(49.4 \%)$ & $128(51.0 \%)$ & \\
\hline \multicolumn{7}{|l|}{ Eye } \\
\hline OD & $521(53.6 \%)$ & $131(54.1 \%)$ & $122(51.9 \%)$ & $134(54.9 \%)$ & $134(53.4 \%)$ & \multirow[t]{2}{*}{$0.925^{\mathrm{b}}$} \\
\hline OS & $451(46.4 \%)$ & $111(45.9 \%)$ & $113(48.1 \%)$ & $110(45.1 \%)$ & $117(46.6 \%)$ & \\
\hline \multicolumn{7}{|l|}{ Injection number } \\
\hline Mean \pm SD & $1.3 \pm 2.1$ & $1.6 \pm 2.3$ & $1.7 \pm 3$ & $1.2 \pm 1.4$ & $0.9 \pm 0.3$ & \multirow[t]{4}{*}{$0.525^{\mathrm{c}}$} \\
\hline Median (range) & $1(0$ to 20$)$ & $1(0$ to 15$)$ & $1(0$ to 20$)$ & $1(0$ to 10$)$ & $1(0$ to 1$)$ & \\
\hline None & $227(23.0 \%)$ & $74(30.1 \%)$ & $73(30.0 \%)$ & $49(19.9 \%)$ & $31(12.4 \%)$ & \\
\hline Any & $758(77.0 \%)$ & $172(69.9 \%)$ & $170(70.0 \%)$ & $197(80.1 \%)$ & $219(87.6 \%)$ & \\
\hline \multicolumn{7}{|l|}{ CMT (micron) } \\
\hline Mean \pm SD & $447 \pm 194$ & $417 \pm 129$ & $452 \pm 152$ & $461 \pm 158$ & $471 \pm 341$ & \multirow[t]{2}{*}{$0.071^{\mathrm{a}}$} \\
\hline Median (range) & $\begin{array}{l}411 \text { (126 to } \\
3650)\end{array}$ & $\begin{array}{l}386 \text { (176 to } \\
830)\end{array}$ & $\begin{array}{l}420(170 \text { to } \\
1270)\end{array}$ & $\begin{array}{l}425 \text { (126 to } \\
1036)\end{array}$ & $\begin{array}{l}425 \text { (205 to } \\
3650)\end{array}$ & \\
\hline \multicolumn{7}{|l|}{ BCVA (logMAR) } \\
\hline Mean \pm SD & $0.64 \pm 0.35$ & $0.61 \pm 0.37$ & $0.65 \pm 0.41$ & $0.6 \pm 0.31$ & $0.69 \pm 0.3$ & \multirow[t]{2}{*}{$0.021^{\mathrm{a}}$} \\
\hline Median (range) & $\begin{array}{l}0.7(-0.3 \text { to } \\
2.6)\end{array}$ & $\begin{array}{l}0.52(-0.3 \text { to } \\
2.09)\end{array}$ & $\begin{array}{l}0.7(-0.18 \text { to } \\
2.6)\end{array}$ & $\begin{array}{l}0.7(-0.3 \text { to } \\
1.61)\end{array}$ & $\begin{array}{l}0.7(-0.3 \text { to } \\
1.79)\end{array}$ & \\
\hline \multicolumn{7}{|l|}{ DX } \\
\hline DME & $845(84.1 \%)$ & $198(78.9 \%)$ & $220(87.6 \%)$ & $213(84.9 \%)$ & $214(85.3 \%)$ & \multirow[t]{3}{*}{$0.038 \mathrm{~b}^{\mathrm{b}}$} \\
\hline AMD & $77(7.7 \%)$ & $27(10.8 \%)$ & $10(4.0 \%)$ & $17(6.8 \%)$ & $23(9.2 \%)$ & \\
\hline RVO & $82(8.2 \%)$ & $26(10.4 \%)$ & $21(8.4 \%)$ & $21(8.4 \%)$ & $14(5.6 \%)$ & \\
\hline \multicolumn{7}{|l|}{ Lens status } \\
\hline Phakic & $730(78.5 \%)$ & $180(78.3 \%)$ & $165(76.0 \%)$ & $201(81.0 \%)$ & $184(78.3 \%)$ & \multirow[t]{3}{*}{$0.875 \mathrm{~d}^{\mathrm{d}}$} \\
\hline Aphakic & $7(0.8 \%)$ & $2(0.9 \%)$ & $1(0.5 \%)$ & $2(0.8 \%)$ & $2(0.9 \%)$ & \\
\hline Pseudophakic & $193(20.8 \%)$ & $48(20.9 \%)$ & $51(23.5 \%)$ & $45(18.1 \%)$ & $49(20.9 \%)$ & \\
\hline \multicolumn{7}{|l|}{ Vitreous reflux } \\
\hline Absence & $684(76.3 \%)$ & $185(80.4 \%)$ & $124(63.3 \%)$ & $185(84.1 \%)$ & $190(76.0 \%)$ & \multirow[t]{3}{*}{$<0.001^{\mathrm{b}}$} \\
\hline Mild & $203(22.7 \%)$ & $43(18.7 \%)$ & $68(34.7 \%)$ & $35(15.9 \%)$ & $57(22.8 \%)$ & \\
\hline Moderate & $9(1.0 \%)$ & $2(0.9 \%)$ & $4(2.0 \%)$ & $0(0.0 \%)$ & $3(1.2 \%)$ & \\
\hline
\end{tabular}

$B C V A$ best-corrected visual acuity, $C M T$ central macular thickness, $S D$ standard deviation

${ }^{a}$ Based on analysis of variance (ANOVA)

${ }^{\mathrm{b}}$ Based on chi-square test

${ }^{\mathrm{c}}$ Based on Kruskall-Wallis test

${ }^{\mathrm{d}}$ Based on Fisher exact test were requested to close their eyes slowly, move the eyes, and avoid squeezing or rubbing, to allow the medicine to be distributed equally over the eye. Anesthetic technique was the same for all participants. No sedation was administered to any patient. The eye and surrounding skin were washed three times with 5\% povidone-iodine solution and then dried with sterile gauze. A sterile plastic drape was then used to keep the eyelashes away from the ocular surface. A sterile speculum was applied to make sure the eyelids remained open. Povidone-iodine (5\%) was again applied to 
Table 2 Comparison of pain, VA, and CMT values and their changes during the study followup among different injection sites

\begin{tabular}{|c|c|c|c|c|c|c|}
\hline & \multirow[t]{2}{*}{ Total } & \multicolumn{4}{|c|}{ Injection site } & \multirow[t]{2}{*}{$p$-Value } \\
\hline & & IN & IT & SN & ST & \\
\hline Pain & $2.9 \pm 2.2$ & $3 \pm 2.3$ & $3 \pm 2.1$ & $1.5 \pm 1.7$ & $4 \pm 2$ & $<0.001$ \\
\hline $\begin{array}{l}\text { Pre-injection BCVA } \\
\text { (logMAR) }\end{array}$ & $0.64 \pm 0.35$ & $0.61 \pm 0.37$ & $0.65 \pm 0.41$ & $0.6 \pm 0.31$ & $0.69 \pm 0.3$ & 0.022 \\
\hline $\begin{array}{l}\text { Post-injection BCVA } \\
\text { (logMAR) }\end{array}$ & $0.49 \pm 0.26$ & $0.42 \pm 0.27$ & $0.53 \pm 0.24$ & $0.48 \pm 0.25$ & $0.5 \pm 0.27$ & 0.008 \\
\hline Change of BCVA & $\begin{array}{l}-0.22 \pm \\
0.27\end{array}$ & $\begin{array}{l}-0.24 \pm \\
0.22\end{array}$ & $\begin{array}{l}-0.31 \pm \\
0.32\end{array}$ & $\begin{array}{l}-0.19 \pm \\
0.26\end{array}$ & $-0.2 \pm 0.26$ & 0.007 \\
\hline Within $p$-value ${ }^{\mathrm{b}}$ & & $<0.001$ & $<0.001$ & $<0.001$ & $<0.001$ & \\
\hline Pre-injection CMT & $447 \pm 194$ & $417 \pm 129$ & $452 \pm 152$ & $461 \pm 158$ & $471 \pm 341$ & 0.071 \\
\hline Post-injection CMT & $277 \pm 212$ & $252 \pm 41$ & $294 \pm 72$ & $277 \pm 386$ & $279 \pm 49$ & 0.828 \\
\hline Change $(\mu \mathrm{m}) \mathrm{CMT}$ & $-170 \pm 284$ & $-138 \pm 91$ & $-124 \pm 67$ & $-182 \pm 349$ & $-195 \pm 338$ & 0.445 \\
\hline Within $p$-value ${ }^{\mathrm{b}}$ & & $<0.001$ & $<0.001$ & $<0.001$ & $<0.001$ & \\
\hline
\end{tabular}

$I N$ inferonasal, $I T$ inferotemporal, $S N$ superonasal, $S T$ superotemporal, BCVA best-corrected visual acuity, CMT central macular thickness

${ }^{\mathrm{a}} p$-Values are based on ANOVA

${ }^{\mathrm{b}} p$-Values are based on paired $t$-test the conjunctiva over the injection site. The entry site of the needle was $3.5 \mathrm{~mm}$ from the limbus in aphakic/pseudophakic patients and $4.0 \mathrm{~mm}$ in phakic patients. All patients received $1.25 \mathrm{mg}$ of bevacizumab in $0.05 \mathrm{~mL}$ intravitreally. All injections were performed using straight injection technique with a 30-gauge needle. Mild pressure was exerted with a swab stick over the injection site to reduce vitreous reflux and prevent subconjunctival hemorrhage. Vitreous reflux was checked in all groups by measuring the width of the broadest conjunctival elevation of the subconjunctival bleb with a surgical caliper described by Rodrigues et al. [25]. Then, a drop of antibiotic was applied to the inferior cul-du-sac.

\section{Statistical analyses}

Demographics and patient characteristics were compared using descriptive statistics and univariate analysis as appropriate. To compare the quantitative variables between injection sites, we used analyses of variance (ANOVAs), and to compare between particular groups, we used independent $t$-tests. To compare nominal variables between injection sites we used chi-square tests. Pearson correlation was used to evaluate the relationship between quantitative variables and pain. Spearman correlation was used to evaluate the relationship between ordinal variables and pain. We used paired-sample $t$-tests to evaluate changes within groups. Effective factors on pain severity were evaluated using simple linear regression analysis. When a variable had a $p$-value $<0.2$ it was included into a general linear regression. Concerning the issue of multicollinearity, when two or more explanatory variables were highly correlated, a variable with the smallest partial correlation coefficient controlling for the highly correlated variables was removed from the set of explanatory variables to be entered in the regression analysis, and variables were recalculated. For comparison between quadrants, Bonferroni correction was applied to account for multiple comparisons. A $p$-value $<0.05$ was considered statistically significant. Data were analyzed using SPSS for Windows, version 24.0 (SPSS Inc., Chicago, IL, USA).

\section{Results}

This study included 1004 eyes of 1004 patients with the mean age of $61.3 \pm 10.4$ years (ranging from 19 to 90 ). Patients' demographics and statistics are summarized in Table 1 . There were 488 men $(48.6 \%)$ and 516 women $(51.4 \%)$. Seven hundred and thirty $(78.5 \%)$ patients were phakic at the time of the intravitreal injection, $193(20.8 \%)$ were pseudophakic, and $7(0.8 \%)$ were aphakic. The indications for bevacizumab injection were DME (84.1\%), AMD (7.7\%), and RVO (8.2\%). Our clinic is a referral center for diabetic patients, thus the majority of our cases were diabetic.

Two hundred and twenty-seven patients (23\%) were naive cases being injected for the first time. The overall mean pain score for all groups was $2.9 \pm 2.2$. The VAS pain scores in the SN, IN, ST, and IT groups were $1.5 \pm 1.7,3 \pm$ $2.3,4 \pm 2$, and $3 \pm 2.1$, respectively. Analysis of pain scores from each site revealed a significant difference in the mean VAS pain scores between groups ( $p<0.001$, ANOVA). In this analysis, the injection in the $\mathrm{SN}$ quadrant was 


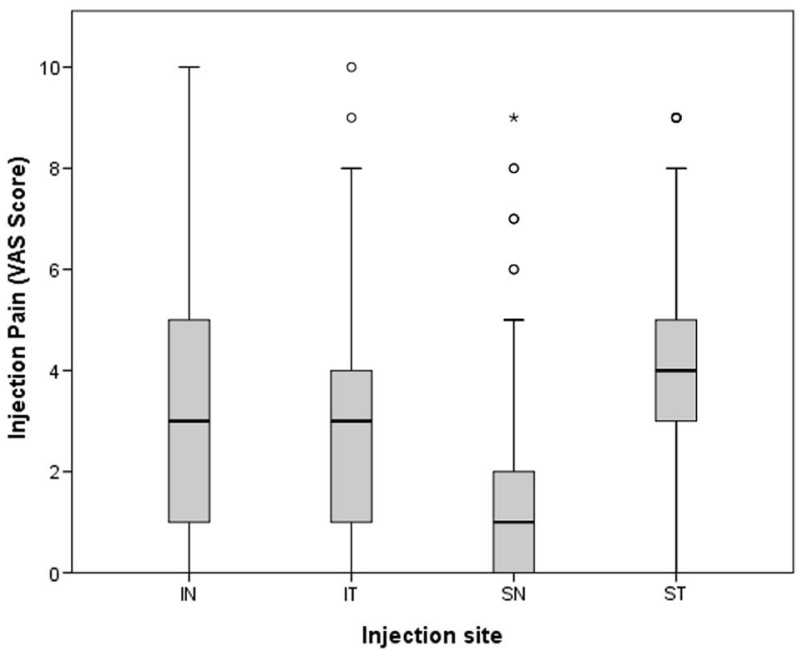

Fig. 1 Distribution and mean pain score in each quadrant

significantly less painful than in other quadrants (Table 2 and Fig. 1) and patients who were injected in the ST quadrant experienced more pain than other patients $(p<$ $0.001)$.

The amount of vitreous reflux was mild in 203 injections (22.7\%), moderate in 9 injections (1.0\%), and absent in 684 injections $(76.3 \%)$ (Table 1). There was no correlation between VAS pain score and amount of vitreous reflux ( $p$ $=0.648$ ) on the multivariate logistic regression analysis based on general linear regression (Table 3).

The difference in the pain scores was not statistically significant between any indications for injection; DME, AMD, and RVO patients $(p=0.390)$. Moreover, with respect to diabetic and non-diabetic patients (AMD + RVO cases), there was no statistically significant difference in pain scores between the two groups $(p=0.604)$.

There was no statistically significant correlation between patient age and VAS score $(p=0.659)$. To find any correlation between patients age and injection pain based on previous studies [26], the patients were divided into two age groups: $>65$ and $\leq 65$ years old. No correlation was found between pain scores and age categories $(p=0.659)$.

A statistically significant correlation was found between patient sex and VAS score $(p<0.001)$.

We found no statistically significant correlation between pain scores of aphakic, phakic and pseudophakic eyes $(p=$ 0.478, ANOVA).

As shown in Table 3, we used general linear model to evaluate the simultaneous relation between the mean VAS pain scores and variables, including injection quadrant, sex, age, indication for injection (diagnosis), history of previous injections, and the number of previous injections. Those variables with a $p$-value $<0.2$ in univariate analysis were included in multivariate analysis. According to Table 3 , the injection site $(p<0.001)$, sex $(p<0.001)$, and the number of previous injections $(p=0.034)$ significantly influenced the VAS pain scores. We found a negative correlation between pain score and the number of previous injections $(p=$ 0.034 , Pearson correlation coefficient $r=-0.067)$. Perceived pain was decreased by increasing number of previous injections (Table 3); this remained statistically significant even after adjusting for other variables in multivariate analysis. Furthermore, changes in CMT $(p=$ 0.445 , ANOVA) were comparable between study groups (Table 2). There were no cases of endophthalmitis, retinal break, retinal detachment, lens damage, severe vision loss, or other serious complications in this study.

\section{Discussion}

Intravitreal injection may become the most common intraocular procedure worldwide in the near future. Therefore, understanding the pain associated with this procedure is important to promote patient comfort and compliance. Our results indicate that the SN quadrant was associated with the least amount of pain during IVB injection.

To the best of our knowledge, the present study is the largest evaluating the severity of pain associated with intravitreal injection. In this study, we used the VAS, which has been widely used in ophthalmologic research $[14,16]$. It was previously validated by trials studying severe postoperative pain and can be easily managed by patients and health-care providers $[27,28]$. Those studies that have been performed to evaluate pain scores during intravitreal injection have presented contradictory results.

Several factors have been reported to be associated with pain during intravitreal injections, such as anxiety [29], sex, number of previous injections, age [30], ketorolac eye drops [26], needle size [20], and anesthetic technique [31].

Moisseiev et al. [16] evaluated the correlation between pain associated with IVB injection and injection site in 218 patients and found no statistically significant difference in terms of pain experienced between anatomical quadrants. However, the results showed a trend toward less pain in the lower-left quadrant. Also, Doguizi et al. [17] investigated pain during intravitreal aflibercept injections in 119 patients and studied variables, including age, sex, indication for the injection, injection site by quadrant (ST or IT), position during injection (sitting or supine), number of previous intravitreal injections in the study eye, presence of DM or hypertension, and lens status (phakic or pseudophakic). They concluded that the pain showed no significant correlation with any of the recorded variables. In contrast, we found a statistically significant difference in terms of pain experienced between anatomical quadrants. We noticed more pain during injections in the ST quadrant and less pain during those in the SN quadrant. An uneven distribution of 
Table 3 The individual and simultaneous relation of possible effective factors and VAS pain score

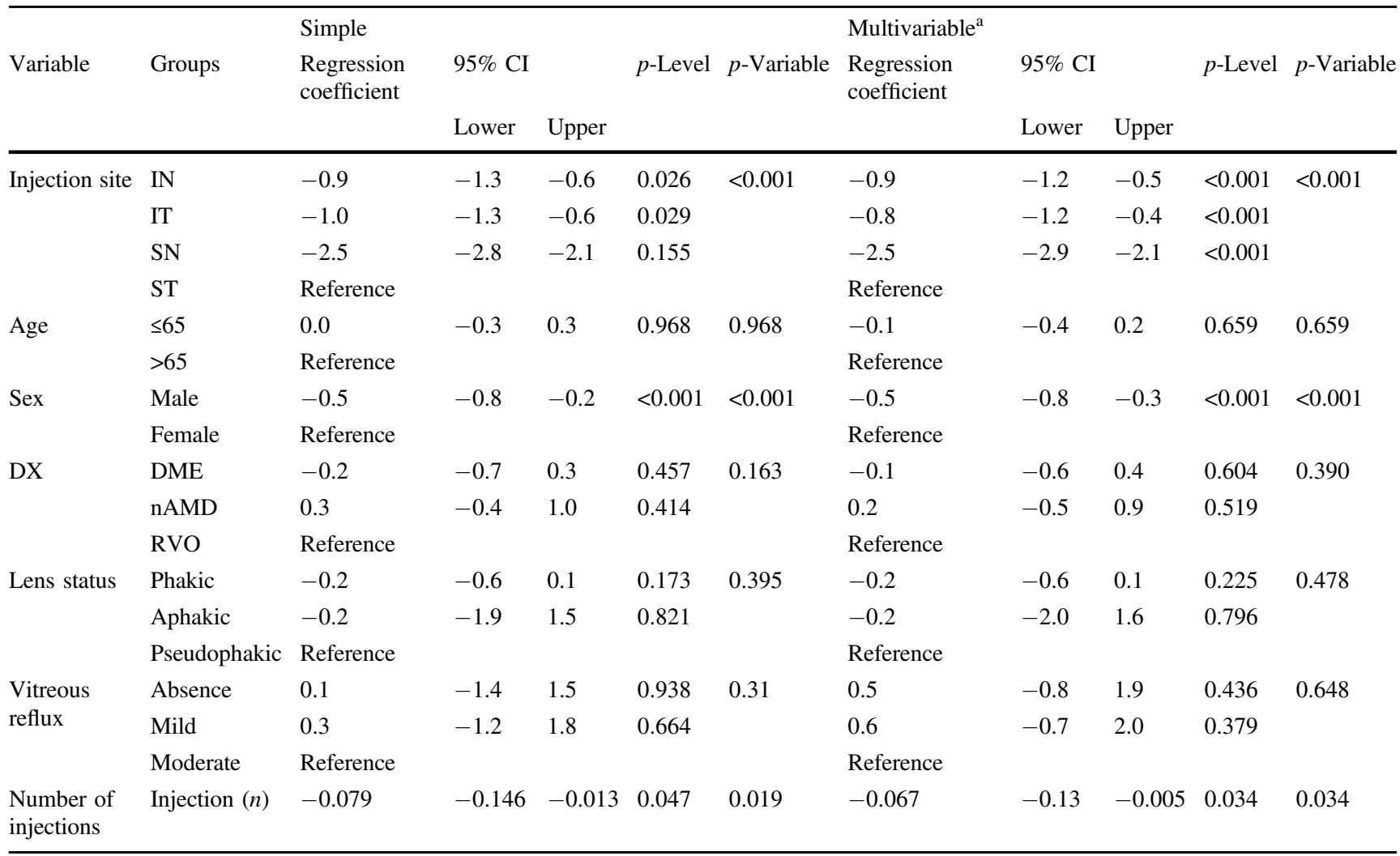

$p$-Level represents the $p$-value for comparison of pain for each level of variable vs. reference level

$p$-variable represents the $p$-value for the relation of each factor (as a whole) and pain score

$I N$ inferonasal, $I T$ inferotemporal, $S N$ superonasal, $S T$ superotemporal, DME diabetic macular edema, $n A M D$ neovascular age-related macular degeneration, $R V O$ retinal vein occlusion

aThose variables that have $p$-value $<0.2$ in univariate analysis included into multivariate analysis based on general linear regression

local anesthetic drug could be a simple explanation for this difference; however, tetracaine eye drops were delivered in the inferior cul-du-sac, and the highest concentration of the drug might not be at the SN quadrant. Additionally, patients were requested to close their eyes slowly, move the eyes, and avoid squeezing or rubbing to allow the medicine to be distributed equally over the eye. Nevertheless, the aspect of pooling of the drug despite ocular movements to dissipate it, remains a strong possibility especially in the supine position and when only two drops were used. The exact reasons for these differences in pain scores between four anatomical quadrants are unclear, and should be investigated in the future studies by mapping the sensory nerves of conjunctiva, episclera, and sclera in all quadrants within 3-4 mm from the limbus, which is the usual site for intravitreal injections.

According to previous studies [32, 33], the stroma of conjunctiva has morphology similar to the end bulbs of Krause, and half of these bulblike compact nerve endings are found in the superior lateral quadrant of the bulbar conjunctiva, which may corroborate our finding. It should be mentioned that most of these structures lay in a narrow 1 $\mathrm{mm}$ wide annular zone of conjunctiva beginning approximately $0.5 \mathrm{~mm}$ from the corneoscleral margin, not close to the site of intravitreal injections [34]. It might have been interesting to have tested the conjunctival sensitivity in each quadrant for every patient using a standard technique.

Moisseiev et al. [16] argued that this trend reflects the technique used by the ophthalmologist who performed the injection, suggesting that less pain is felt when the ophthalmologist is manually comfortable. In our study, all injections were performed by the same surgeon, who was right-handed (similar to the previous study), and approaching the SN quadrant of the eyes with the needle was not convenient. Hence, our results do not support the theory that pain related to intravitreal injections is minimal when the ophthalmologist performing the procedure is most physically relaxed. However, given the awkwardness of the SN quadrant, which is the least-sensitive site, the risk of technique-related complications may be higher.

The mean VAS score in the present study was $2.86 \pm 2.2$. In general, this is relatively high compared to that observed 
in a previous study by Shiroma and associates [33]. This may be in part responsible for our reported correlations. The higher VAS scores may be due to the method of anesthesia - only two drops of tetracaine. In our study, perceived pain during intravitreal injection was mild (VAS scores between 5 and $44 \mathrm{~mm}$, on a $0-100 \mathrm{~mm}$ scale) similar to that observed in a previous study [31], Blaha et al. [19] reported a mean pain score of 2.8 in a topical tetracaine group. Andrade et al. [35] reported a pain score of $3.2 \pm 1.7$ for topical proparacaine patients. Thus, although the mean pain score in our study may be relatively higher than that in most previous studies, this is not surprising.

It has been shown that the nerve density decreases with age, particularly past the age of 70 , which suggests that older patients should experience less pain during intravitreal injection [36]. However, we found no association between pain severity during intravitreal injection and age. In our study, most subjects were younger than 70 years old, which may be one reason why we failed to find a significant correlation between age and pain score.

Rifkin and Schaal [30] demonstrated that females reported lower post-injection pain scores. To the contrary, Pieramici et al. [5] and Doguizi et al. [17] reported no statistically significant difference in pain scores between females and males. Contrary to previous studies, we found that sex was a significant contributor, such that females reported higher pain scores during IVB $(p=0.001)$ even after adjusted in multivariate regression analysis (Table 3). Similarly, Haas et al. [37] reported higher VAS pain scores in females. They suggested that females are more sensitive than males to noxious stimuli and have lower levels of stress-induced analgesia. We think that the different pain scores between female and male patients may be related to educational and cultural differences, and may not be clinically important.

In the present study, a negative correlation was found between pain and the number of previous injections $(p=$ 0.05 ) using univariate analysis. Since the $p$-value was $<0.2$, it was included into multivariate analysis, and remained a significant factor $(p=0.03$, regression coefficient $=$ $-0.067)$. This may be partly related to the decrement of the patient's anxiety after multiple injections. In addition, Segal and associates [32] and Chen et al. [38] reported a significant relationship between pre-procedural anxiety and perceived pain in intravitreal injections. They concluded that decreased anxiety might lead to reduced pain and it might be beneficial to explore ways to reduce anxiety (like listening to classical music) during outpatient intravitreal injections.

In the present study, we did not find any correlation between pain scores and indication for injection $(p=0.16)$. Similarly, Doguizi et al. [17], Moisseiev et al. [16], and Rifkin and Schaal [30] did not find any significant difference in the pain scores between indications. It is well known that diabetes causes neural changes to the cornea; however, changes in the sclera are not well characterized $[39,40]$. A pilot study by Cook et al. [41] demonstrated no association between scleral thickness and diabetes. Conversely, Zinkernagel et al. [42] showed that intravitreal injections might lead to scleral thinning when applied repeatedly in the same quadrant. In other words, in diabetic patients, corneal sensitivity may be reduced, but changes in scleral thickness and sensitivity are unclear. In our study, the majority of patients were diabetic, but both diabetic and non-diabetic patients needed multiple injections. We found no significant difference in pain scores between diabetic and non-diabetic patients.

The strong points of our study include a large sample size, a prospective and randomized design, and the evaluation of the influence of different diseases on pain severity. However, our study had some limitations, including the fact that it was conducted in a single hospital and relied on using VAS scoring, which is known to be subjective.

In conclusion, this study provides a description of the contribution of various factors to pain associated with intravitreal injection. Sex, injection site, and number of previous injections appear to significantly contribute to pain severity, independently. Since there are slight anatomical differences between quadrants, we assume that increased pain is associated with locations in which there are more compact nerve endings. Consequently, we suggest choosing the SN quadrant for intravitreal injection in patients who complain of previous painful intravitreal injection.

\section{Summary}

\section{What was known before:}

- Despite the common use of intravitreal injections, there are no uniform clinical guidelines or consensus on the site or quadrant location used for injection, which varies according to the surgeon's discretion.

\section{What this study adds:}

- This study showed that pain severity score was significantly associated with injection site, number of injections, and sex.

Acknowledgements The authors would like to thank Masumeh Kalantarion, Masoumeh Zarei, and Marzieh Rahimi for cooperation in the current study and the eye clinic staff working at Torfeh Hospital for 
their valuable help during the entire process of this study. This paper was presented as an oral presentation at the European Society of Retinal Specialists meeting (Euretina 2017), Barcelona, Spain.

Author contributions Involved in design and conduct of the study: SK and $\mathrm{KJ}$; collection, analysis, and interpretation of the data: SAM, BK, and $\mathrm{HN}$; and preparation and review of the manuscript: SAM, SK, and HN. This study was registered on clinical trials.gov (identifier, NCT02790775).

\section{Compliance with ethical standards}

Conflict of interest The authors declare that they have no conflict of interest.

\section{References}

1. Peyman GA, Lad EM, Moshfeghi DM. Intravitreal injection of therapeutic agents. Retina. 2009;29:875-912.

2. Gunther JB, Altaweel MM. Bevacizumab (Avastin) for the treatment of ocular disease. Surv Ophthalmol. 2009;54:372-400.

3. Rosenfeld PJ, Brown DM, Heier JS, Boyer DS, Kaiser PK, Chung $\mathrm{CY}$, et al. Ranibizumab for neovascular age-related macular degeneration. N Engl J Med 2006;355: 1419-1431.

4. Brown DM, Kaiser PK, Michels M, et al. Ranibizumab versus verteporfin for neovascular age-related macular degeneration. $\mathrm{N}$ Engl J Med. 2006;355:1432-44.

5. Pieramici DJ, Rabena M, Castellarin AA, et al. Ranibizumab for the treatment of macular edema associated with perfused central retinal vein occlusions. Ophthalmology. 2008;115:e47-54.

6. Avery RL, Pearlman J, Pieramici DJ, et al. Intravitreal bevacizumab (Avastin) in the treatment of proliferative diabetic retinopathy. Ophthalmology. 2006;113:1695-705.

7. Heimann $H$ (2007). Intravitreal injections: techniques and sequelae. In: Holz FG, Spaide RF, editors. Medical retina (essentials in ophthalmology). 1st ed. Berlin: Springer-Verlag, p. 67-87.

8. Segal O, Segal-Trivitz Y, Nemet AY, et al. Survey of intravitreal injection techniques among retina specialists in Israel. Clin Ophthalmol. 2006;10:1111-6.

9. Xing L, Dorrepaal SJ, Gale J. Survey of intravitreal injection techniques and treatment protocols among retina specialists in Canada. Can J Ophthalmol. 2014;49:261-6.

10. Shiroma HF, Rodrigues EB, Farah ME, et al. Safety and efficacy of various concentrations of topical lidocaine gel for intravitreal injection. Expert Opin Drug Saf. 2014;13:1299-303.

11. Shiroma HF, Farah ME, Takahashi WY, et al. Survey: technique of performing intravitreal injection among members of the Brazilian Retina and Vitreous Society (SBRV). Arq Bras Oftalmol. 2015;78:32-5.

12. Anijeet DR, Hanson RJ, Bhagey J, Bates RA. National survey of the technique of intravitreal triamcinolone injection in the United Kingdom. Eye. 2007;21:480-6.

13. Green-Simms AE, Ekdawi NS, Bakri SJ. Survey of intravitreal injection techniques among retinal specialists in the United States. Am J Ophthalmol. 2011;151:329-32.

14. Tewari A, Shah GK, Dhalla MS, Blinder KJ. Surface anesthesia for office-based retinal procedures. Retina. 2007;27:804-5.

15. Prenner JL. Anesthesia for intravitreal injection. Retina. 2011;31:433-4.

16. Moisseiev E, Regenbogen M, Bartfeld Y, Barak A. Evaluation of pain in intravitreal bevacizumab injections. Curr Eye Res. 2012;37:813-7.
17. Doguizi S, Sekeroglu MA, Inanc M, et al. Evaluation of pain during intravitreal aflibercept injections. Eur J Ophthalmol. 2018;28:63-7.

18. Yau GL, Jackman CS, Hooper PL, Sheidow TG. Intravitreal injection anesthesia - comparison of different topical agents: a prospective randomized controlled trial. Am J Ophthalmol. 2011;151:333-7.

19. Blaha GR, Tilton EP, Barouch FC, Marx JL. Randomized trial of anesthetic methods for intravitreal injections. Retina. 2011;31:535-9.

20. Rodrigues EB, Grumann A Jr, Penha FM, et al. Effect of needle type and injection technique on pain level and vitreal reflux in intravitreal injection. J Ocul Pharm Ther. 2011;27:197-203.

21. Knecht PB, Michels S, Sturm V, et al. Tunnelled versus straight intravitreal injection: intraocular pressure changes, vitreous reflux, and patient discomfort. Retina. 2011;29:1175-81.

22. Amoaku W, Pearce I, Browning A. Guidelines for intravitreal injections procedure. London: The Royal College of Ophthalmologists; 2009. http://www.rcophth.ac.uk

23. Ruiz-Moreno JM, Arias-Barquet L, Armadá-Maresca F, et al. Guidelines of clinical practice of the SERV: treatment of exudative age-related macular degeneration (AMD). Arch Soc Esp Oftalmol. 2009;84:333-44.

24. Sanabria MR, Montero JA, Losada MV, et al. Ocular pain after intravitreal injection. Curr Eye Res. 2013;38:278-82.

25. Rodrigues EB, Meyer CH, Grumann A, et al. Tunneled scleral incision to prevent vitreal reflux after intravitreal injection. Am J Ophthalmol. 2007;143:1035-7.

26. Rifkin L, Schaal S. Shortening ocular pain duration following intravitreal injections. Eur J Ophthalmol. 2012;22:1008-12.

27. LaHood BR, Sherwood D, Suter A. Comparative assessment of the effectiveness of anaesthesia for intravitreal bevacizumab injection. Clin Exp Ophthalmol. 2011;39:184-5.

28. Kaderli B, Avci R. Comparison of topical and subconjunctival anesthesia in intravitreal injection administrations. Eur J Ophthalmol. 2006;16:718-21.

29. Segal O, Segal-Trivitz Y, Nemet AY, et al. Anxiety levels and perceived pain intensity during intravitreal injections. Acta Ophthalmol. 2016;94:203-4.

30. Rifkin L, Schaal S. Factors affecting patients' pain intensity during in office intravitreal injection procedure. Retina. 2012;32:696-700.

31. Shiroma HF, Takaschima AKK, Farah ME, et al. Patient pain during intravitreal injections under topical anesthesia: a systematic review. Int J Retin Vitr. 2017;3:23.

32. Oppenheimer DR, Palmer E, Weddell G. Nerve endings in the conjunctiva. J Anat. 1958;92(Pt 3):321-52.5.

33. Riisager PM. A clinical study of the numerical variation with age of compact nerve endings in the human conjunctiva. J Neurol Neurosurg Psychiatry. 1962;25:134.

34. Lawrenson JG, Ruskell GL. The structure of corpuscular nerve endings in the limbal conjunctiva of the human eye. J Anat. 1991;177:75-84.

35. Andrade GC, Carvalho AC, de Andrade GC, et al. Comparison of 3 different anesthetic approaches for intravitreal injections: a prospective randomized trial. Arq Bras Oftalmol. 2015;78:27-31.

36. He J, Bazan NG, Bazan HE. Mapping the entire human corneal nerve architecture. Exp Eye Res. 2010;91:513-23.

37. Haas P, Falkner-Radler C, Wimpissinger B, et al. Needle size in intravitreal injections-pain evaluation of a randomized clinical trial. Acta Ophthalmol. 2016;94:198-202.

38. Chen X, Seth RK, Rao VS, et al. Effects of music therapy on intravitreal injections: a randomized clinical trial. J Ocul Pharmacol Ther. 2012;28:414-9.

39. Cousen P, Cackett P, Bennett H, et al. Tear production and corneal sensitivity in diabetes. J Diabetes Complicat. 2007;21:371-3. 
40. Tavakoli M, Kallinikos PA, Efron N, et al. Corneal sensitivity is reduced and relates to the severity of neuropathy in patients with diabetes. Diabetes Care 2007;30: 1895-1897.

41. Cook R, Haslam B, Lundquist MB, et al. Anterior Scleral Thickness Changes in High Myopia and Diabetes Measured by Anterior Segment OCT: A Pilot Study, 2014; http://www.aaopt.org.
42. Zinkernagel MS, Schorno P, Ebneter A, Wolf S. Scleral thinning after repeated intravitreal injections of antivascular endothelial growth factor agents in the same quadrant scleral thinning after injections of anti-VEGF. Invest Ophthalmol Vis Sci. 2015;56:1894-900. 